Journal of Applied Pharmaceutical Science Vol. 6 (09), pp. 220-226, September, 2016

Available online at http://www.japsonline.com

DOI: $10.7324 / \mathrm{JAPS} .2016 .60933$

ISSN 2231-3354 (cc)) EY-NC-SA

\title{
Bio-Nanotechnology for Active Food Packaging
}

\author{
Deepansh Sharma*, Daljeet Singh Dhanjal \\ School of Bioengineering and Biosciences, Lovely Professional University, Phagwara-144411, India.
}

\section{ARTICLE INFO}

Article history:

Received on: 18/06/2016

Revised on: 22/07/2016

Accepted on: 19/08/2016

Available online: 26/09/2016

Key words:

Bio-nanotechnology, Food

packaging, Nano-composites,

Nano-emulsions and edible

packaging films.

\begin{abstract}
The most commonly used packaging material is associated with environmental issues as they are nondegradable in nature. The number of attempts are made for developing the eco-friendly degradable biopolymers as ideal food packaging. The biopolymers developed are not commercialized as they have poor mechanical strength and resistance properties. Thus to enhance the following faults in the reinforcing material are added which resulted in the composites formation. During various food processing operations the nanotechnology approach is employed such as encapsulation of the material in the nanoparticles, which can be delivered to the targeted site, enhancement of the flavor, integration of antibacterial agents with the nanoparticle in the food, enhancement of shelf-life for storage, and contamination sensing. Food packaging substances synthesized by nanotechnology may increase the shelf-life of the food as they provide resistive packaging, increase the level of food safety, liberate the preservatives for enhancing the life of the food and notify the consumer either the food is consumable or spoiled. Nano-supplements are integrated by the encapsulation method for efficient dietary as well as drug delivery systems. Nano-materials are not well evaluated for the health risk and environmental issues associated with it even the side-effects are unexploited. Various authorities are working prompt designing of guidelines and legislation policies for further acceptance of Nano-based materials in food packaging systems. Biologically synthesized nanoparticles will serve as a significant tool to conquer present contests that are linked with food packaging constituents.
\end{abstract}

\section{INTRODUCTION}

Nano-technology is the convergence of distant domains of engineering, physics, chemistry, and material science and modern molecular biotechnology (Huang et al., 2007; Rai et al., 2008). In this present century, Nano-technology became the most recognized technology which revealed its ability to synthesize new products with diverse applications and advantages. Nanoparticles synthesized by biotechnological aid is done with the help of living entities such as bacteria (Farhoodi, 2016; Khalaj et al., 2016; Castro-Mayorga et al., 2016; Couch et al., 2016; Souza and Fernando, 2016; Shahverdi et al., 2007; Dhandapani et al., 2014; Mohite et al., 2015), fungi (Ahmad et al., 2014; Govender et al., 2009), actinomycetes (Manivasagan $e t$ al., 2015; Ahmad et al., 2003), algae (Sudha et al., 2013; Govindaraju et al., 2009). It has been reported that micro-

* Corresponding Author

Email:deepanshsharma@gmail.com organism secrete different kinds of proteins that have the ability to reduce the metal-ion (Thakkar et al., 2010). Biotechnologically synthesized nanoparticles are on the path of greener and ecofriendly environment. Biogenic synthesis approach used for the production of nanoparticles showed non-toxic affects as compared to the chemical synthesis approach which involves the toxic chemicals as well as require optimum conditions for its processing (Tyagi et al., 2015; Gade et al., 2008; Mukherjee et al., 2008). Bio-nanotechnology is firmly being used in the areas like food production and packaging (Sharma and Saharan et al., 2016; Saharan et al., 2013; Duncan et al., 2011; Sorrentino et al., 2007; Kuzma et al., 2008; Sanguansri and Augustin, 2006). Nanotechnology shows promising results for improving the quality of the food, health and safety as their ability to alert the consumer for its spoilage. Nanoparticles are unlike from conventional materials in stipulation of having increased relative surface area which improve strength, reactivity and electrical properties (Boccuni, et al., 2008; Kahn et al., 2006). 
Nanoparticles may be used to make packaging material with improved mechanical and thermal performance (Sharma et al., 2014; Sorrentino et al., 2007).

Nanoparticle based delivery models could be employed for the delivery of the functional foods to their targeted sites of action (Weiss, 2006). Elementary as well as the applied researches performed in the field of physics, chemistry, biology and material sciences have inspired the current Industrial development sector to employ these approaches in collaboration with the conventional approaches.

\section{Scope of nanotechnology in packaging material}

Synthesis of nanomaterial is a prevailing interdisciplinary approach for the creation of innovative sustainable products. Globally, it has been expected that nanoparticle based industry will influence at least \$3 trillion about the world by 2020 (Duncan, 2011). Nano particle based packaging materials for the food industries (A Global Technology, Industry and Market Analysis 2009). According to worldwide development predictions are being made that bio-nanotechnology will be responsible for a noteworthy thrust in the development of innovative food packaging methods. The biggest concern of the food industries is on the increasing the shelf-life of the food products which can be attained by encapsulated protective coating and advanced packaging system developed on the basis of these approach.

Currently severe environmental crisis are being faced because the unavailability of method of degrading the food packaging materials such as plastic. Novel biotechnological based material and formulations are being designed to formulate edible and eco-friendly biodegradable films to extend shelf life of food at the same time also drop the rate non-degradable packaging material (Prashanth and Tharanathan, 2003). The emergence of the bio-nanotechnology approach for synthesizing bio-polymers may unlock new path for developing packaging material which will be cost-effective (Sorrentino et al., 2007). The incorporation of the nano-composites within the packaging material has been reported to increase the strength and thermal stability (Lagaron et al., 2005; De Jong et al., 2005; Jakubinek et al., 2010). The usage of the Nano-technology is now not limited to the packaging technology but is now effectively used in the functional foods (Chen et al., 2006). Reports states that with addition of the nano-composite in the edible increase their shelf-life (Lagaron et al., 2005; Sinha et al., 2005).

Till date majority of food packaging methods developed were associated with metal or oxide particles. Packaging material developed by Nanotechnology are alleged to be valuable. Indispensable faith is show by the food industry towards the nanotechnology food in the market (Weiss et al., 2006). On observing the todays scenario nanotechnology permits the initiation of innovative abilities to the material which in return provides enormous advantages. The usage of these material may also be associated with some unknown threats (Pusztai and Bardocz, 2006). The unique properties of nano-materials and the sudden expansion of nano-material based products also raised several concerns over their consequences for human and environmental health.

\section{Bio-Nanotechnology for food packaging}

The need of developing new food packaging system are concerned for increasing the shelf-life by preventing the spoilage. Bio-nanotechnology offers advanced expectation from food packaging that will provide the longer shelf-life, secure packaging with improve traceability of food quality. Intellect food packaging can alert on spoilage to the consumer whereas during the active packaging addition of preservatives like antimicrobials are added into the food during the initiation of the spoilage (Duncan, 2011; Zheng et al., 2004; Habib et al., 2008). Revolution in the food packaging took place due to the emergence and integration of nano-composites, nano-sensors, where nano-composites provide advantages like proofing from leaks, gases and pathogen in food packaging techniques. By the incorporation of the silver titanium oxide, zinc oxide and other bio-nanoparticles act as a barrier for the exchanging gases and additionally prevents the growth of bacteria, fungi or any other pathogens. Improved barrier abilities can aid in maintaining the quality of the food and increase the shelf-life excluding the supplemented chemical preservers etc.

\section{Application of Nanoparticles in Food Packaging Nano Encapsulation}

Nano-encapsulation can be described as a technology to pack material in miniature with the assistance of methods such as nano-composite, nano-emulsification, nano-structuration and gives finished product with extensive functionality that involves controlled release of the core. Nano-encapsulation system presents various benefits (Mortazavi et al., 20102) together with ease of handling, improved stability, withholding volatile components, controlled moisture release, $\mathrm{pH}$-triggered controlled release, and enhanced bioavailability and efficacy (Eltayeb et al., 2015; Quintanilla-Carvajal et al., 2014). Nano encapsulation have been tested for the safe and controlled discharge of favorable live probiotic cells to boost healthy gut function. The sustainability of probiotic organism such as Lactobacillus acidophilus, Lactobacillus casei, Lactobacillus rhamnosus, and Bifidobacterium spp. which are present in the freeze-dried yogurt can be amended through nano-encapsulation with the help of calcium alginate (Kailasapathy and Rybka, 1997).

\section{Nano Composite}

Nano-composite material comprises of two or more phase, from which one phase work as continuous phase whereas the second phase work as the disperse phase. Usually, polymer part used is a continuous phase and the reinforcing material is the disperse phase. Commonly, nano-composites are those containing polymers with one organic or inorganic disperse phase i.e. reinforcing material with a dimension lesser than $100 \mathrm{~nm}$. Biodegradable polymers which are made from renewable source, regularly exploited for the production of nano-compositesare polylactide (PLA), chitosan, cellulose acetate, thermoplastic 
starch and isolated whey protein (Rhim et al., 2011; Jamshidian et al., 2010; Matthey et al., 2007; Kampeerapappun et al., 2007; Kim and Yun, 2006). The assimilation of different nanoparticles such as $\mathrm{SiO}_{2}$, clay, $\mathrm{TiO}_{2}, \mathrm{KMnO}_{4}$, nano cellulose, nano fibrillated cellulose and carbon nanotubes are capable of amending the packaging material in terms of mechanical and barrier properties (Tsai et al., 2010; Reddy et. al., 2007; Xie et al., 2012; Hejri et al., 2013; Saeidnia et al., 2013; Mukherjee et al., 2014; Yang and Yao, 2014). It has been reported that packaging material mechanical properties such as ductile strength, shear strength, barrier potential, thermal constancy and optical characteristics of polymers can be enhanced by assimilating nano materials into their matrices (Zhong et al., 2007).

The blending of antimicrobial agents within the food packaging products has been extensively approved. The spoilage by the pathogenic microorganism can be restraint to greater extent by usage of the antimicrobial films (Huang et al., 2005; Kumar $e t$ al., 2005). The film synthesized with antimicrobial Nano composite drew attention due to its structural sustainability and barrier properties provide because of the nano composite matrix (Luo and Stutzenberger, 2008).Several nanoparticles like gold, silver, zinc, and other metal oxides have been used in different food packaging applications (Zhuang et al., 2011; Duncan, 2011; Llorens et al., 2012). ). In many reports it has been determined that silver metal nanoparticles can breach into the membranes of the cells. Additionally, silver nanoparticles have been recognized for their capability to constrain different respiratory process enzymes and impede the infiltration of protons and phosphate through the cell membrane, ultimately decreasing the ATP production levels well contained by the cell. Agar films incorporated have the antimicrobial activity of the resulting nano composites, considerable rise in antimicrobial potential against Listeria monocytogenes (gram positive) and Escherichia coli O157:H7 (gram-negative) pathogens (Kanmani and Rhim, 2014). Antimicrobial properties against E. coli and Staphylococcus aureus have been reported on with lots of nano-composite systems, comprising polymer and silver nanoparticles (Fortunati $e t$ al., 2013) chitosan based packaging material containing silver nanoparticles (Sanpui et al., 2008; Sadeghnejad et al., 2014).

Antimicrobial nanocomposite films prepared with gelatin and silver nanoparticles and organo-clay showed significant antimicrobial activity. Even significant anti-bacterial activity is shown against the food borne pathogen by the nano composite film. Results suggested that the use of gelatin based nanocomposite films will help to compete and eradicate the bacterial invaders and to improve the shelf life and food quality (Paulraj and Rhim, 2014). Methylcellulose modulated with nanosized silver demonstrated enhanced mechanical properties i.e. the incorporation of $\mathrm{Ag}$ directed to both strengthening and toughening of polymer. The antimicrobial activity against diverse microorganism exhibited by methylcellulose-silver nano composite films (Maity et al., 2012).Antimicrobial activity influenced by the nanocomposites size, amount of silver nanoparticles, and amount of monomeric acid existing inside the hydrogel-silver nanocomposites. It has been established that absorption of plain hydrogel in $20 \mathrm{mg} / 30 \mathrm{ml} \mathrm{AgNO}_{3}$ solution generates optimal bacterial activity of nanohydrogel composites (Burg et al. 2007). Even though nanoparticles are capable in controlling bacteria but still lots of research gap to look into the effectiveness of metal nanoparticles on pathogenic bacteria and its regulation sides

\section{Nano Emulsions}

The operations such as the targeted delivery of lipophilic products for example nutraceuticals, medicines, flavor, antioxidants and antimicrobial agents are accomplished by thee carriers named nano-emulsions (Kesisoglou et al., 2007; Sanguansri and Augustin, 2006). Nano-emulsion comprises of lipid phase present in the liquid phase, in which each oil droplet is encapsulated by the thin interfacial. Usually due to their comparatively miniature size, nano-emulsion are very stable to gravitational separation (McClements, 2009). Bioavailability of the captured components can also be enhanced through the nonemulsion assisted delivery systems due to their relative smaller size as well as more surface to volume ratio (Acosta, 2009). The large range of approaches are devised for industrialized production of the lipophilic functional compounds of nano size dimensions. The methods employed for these purposes include approaches requiring high or low energy which are emulsificationevaporation, emulsification-diffusion, solvent displacement, and precipitation (Acosta, 2009). Though most of the techniques are in the development stage, they authorize the preparation of extremely fine component of nano-dispersions (Horn and Rieger, 2001). Nano-emulsions often show consistency in terms of particle accumulation and separation due to gravity. The particles that are trapped within the nano-emulsions scatters light waves very weakly, which make it suitable for amalgamation for products which are needed to optically clear like carbonated drinks, soups, ketchups and dips (Wooster et al., 2008). The highly viscous or gel like product can be formed from nano-emulsion that also at low concentration as compared to the traditional emulsions which may be associated with other functions in food products. The nanoemulsion in many studies is stated as a most prominent way for capturing and transporting antimicrobial agent to the targeted site (Teixeira et al., 2009; Ferreira et al., 2010). Even for the decontamination of the food packaging equipment and function associated with varieties of food surfaces are accomplished with antimicrobial nano-emulsions (Sekhon, 2010). Due to the various advantages, nano-emulsion technique can be employed in the food, brewed and pharmaceutical products preparation for the targeted transportation, efficiently use in the products which needs to optically clear and enhance the bioavailability of the active compound when needed.

\section{Edible Nano Coatings and Nano Coating Materials}

Generally, edible films and coating can be described as thin-continuous layer of edible component expended as coating or 
a film among the food material to facilitate a barrier to mass transfer (Baldwin et al., 1996; Banks, 1993). They primarily diverge in the mode of formation and application to foods. Edible coating is done with the help of liquid film forming solution onto the surface of the food products. They are created by casting or by traditional plastic extrusion techniques (Park et al., 1996).

Films made from edible comprises of water-soluble polysaccharides (hydrocollids) and lipids. The most commonly used polysaccharides are cellulose derived such as alginates, pectins. Starches, chitosan and other polysaccharides. Polysaccharides gives variety of properties like rigidity, firmness, thickening quality, viscosity, adhesive and gel-forming capability. Different types of lipid complexes like animal and vegetable fats have been employed for synthesizing the edible films and coatings. Mainly used lipid molecules are waxes, acylglycerols and fatty acids. Lipid films provide barrier against moisture and adds gloss touch to the confectionary products. Edible coating and films are the convenient means for adding additives and supplementary ingredients to amend the color, texture, and additionally prevents the microbial growth (Siragusa and Dickson, 1992). For the material in which nano-coating is required for that the nanoparticles are used on the packaging material cover or can be incorporated as a nano laminate layer. Reports comparing multilayer films with nano-coating shows advantages such as reduced material usage and stress-free film conversion method. The reports are documented for assessment of antimicrobial capability of the nano-structured coatings integrated with ecofriendly and non-biodegradable polymer used for active food packaging (Vaha-Nissi et al., 2010). ZnO coating improved the antibacterial potential of a PVC film (Li et al., 2010). The nanoparticles of $\mathrm{TiO}_{2}$ consisted nano-coating was also described as an efficient system against $E$. coli $(\mathrm{Fu}, 2010)$. The nanostructured composited synthesized with the help of calcium silicate nano materials has been also reported for its utility as the surface coating and also about its antimicrobial activity. Recent advances in food packaging solutions depicted the apparent use of the nanostructured coating which facilitate in the water repellent properties of paper made for packaging solutions. In alternative findings, paper surface of the paper was treated R812S silica nanoparticles and Polydimethylsiloxane (PDMS) silicone oil to exhibit super hydrophobic surface like lotus. The R812S silica nanoparticles and Polydimethylsiloxane (PDMS) silicone oil revealed that this complex is highly water resistant because of its unique nanostructured morphology. The efforts are being made to develop $\mathrm{TiO}_{2}$ nanoparticles coating to provide hydrophobic property to the paper with the help of liquid flame spray technique (Teisala et al., 2012). $\mathrm{TiO}_{2}$ and $\mathrm{Ag}$ nanoparticles were synthesized and coated onto a paper prepared from rice straw. Results showed that $\mathrm{TiO}_{2}$ and $\mathrm{Ag}$ nano-composites are potent antimicrobial and barrier packaging system (Youssef et al., 2013).

\section{Safety Evaluation of Nano-Packaging Material}

The concern about health and environment welfare came into existence as the new properties of nano-materials are being exploited and growth in consumption of nanomaterial based products (Helland et al., 2006). The reports have been published which informs about harmful effect on humans on exposure of nanomaterial (Borm et al., 2006). A large number of recent evidence have been created describing how nano-material based processes and products may hinder prior to establishment of guidelines for human health (Borm et al., 2006). Even the great potential is shown by the nanotechnology in varied industrial sectors. From that bio-nanotechnology has received the great appreciation from society for its ability and role in food packaging system. This may lead to develop economical product in short span. The concern related to health and environmental risk by nanomaterials are in their primary screening stage, where side effects are not well-defined. Due to which usage of natural biodegrading material and recycling of nanomaterial are prohibited. It is also uncertain that many nanoparticles have the ability to cease the development of beneficial bacteria that are present in the environment and in the digestive tracts like probiotics (Kuzma et al., 2006).The British Standards Institution, International and European Committee for Standardization, and OECD have undertaken all the ethical, social and demand issues related to nano safety including the vocabulary related to nanotechnology, classification, validated measurement and characterization procedures. The two main issue of significance. From which the primary issue is concerned with food safety and condition which can have possible influence on consumer. The major concern is that nanomaterial used in packaging and targeted delivery system have any adverse effect on the protection of food. The successive query is related to the environmental issue which is associated with recycling and change in the recycling systems because of the usage of nanomaterial (Tiede et al., 2008). No effective instrument is yet developed to test packaging material track nanomaterial within the food. There is scarcity of knowledge about the influence of nanomaterial in waste disposal. Additionally, there is no attention given to nanomaterial that is present in the packaging system during recycling, incinerating for energy revival and liberation in landfills (Tiede et al., 2009).

The government federation like European Union (EFSA; the European Food Safety Authority) and the United States of America (US-FDA; the Food \& Drug Administration) gave the report illustrating one advantage of nanomaterial for packaging which is limited to the material made of plastics. The EU and USA are model of regulatory bodies which pass the agreement by assessing the safety norms enquiring about constituents required for plastic food packaging. The assessment of safety is entirely based on the chemistry and toxicity details which are provided by the aspirant according to the data requirements passed by government agencies.

\section{Future perspective and conclusion}

The importance of nanotechnology is increasing for the food industry. New protocols are being explored which assure valid results and applications in the domain of food packaging system. Developing countries are also benefited as they can 
establish new market for novel nanomaterials and manufacturing processes as nanotechnology has great potential. It is projected that the next generation of intellectual packaging will allow an improved monitoring of the flow, protection and excellence of food materials. With addition of suitable nano-particles, it is easy to synthesize packaging material of intense tensile strength, resistance and thermal performance. The incorporated nanosensors in the packaging system warn the consumer on spoilage. The ability of the field of nanotechnology and its benefits are needed to be explored in the concern of industry and human health. Similarly definite policies have to be made by the food organizations to launch proper and safe commercialization of nano based food applications.

The edible nano-laminates got the access in the fresh fruits and vegetables, confectionary products and formulation, due to its ability to provide barrier from water, lipids, gases, odors and off-taste. Besides many nanomaterial provides extensive properties to the packaging material like antimicrobial activity, oxygen reducing activity, immobilization of enzyme and warning of degradation of the contaminated food.

The two main concern of importance involves issue related to food safety and quality that may affect the consumer and second issue is related to environment safety. The international and regional industries have now reduced the gap by delivering and enclosing the rule of nanotechnology usage in foods, food additives and packaging material. Significantly, the accomplishment of nanotechnology in the food and bioprocessing industry is determined by alertness in the society and consumers. In conclusion, bio-nanotechnology will help as a significant approach to conquer present defies that are linked with active food packaging solutions.

Financial support and sponsorship: Nil.

Conflict of Interests: There are no conflicts of interest.

\section{REFERENCE}

Acosta E. Bioavailability of nanoparticles in nutrient and nutraceutical delivery. Current Opinion in Colloid \& Interface Science. 2009; 14(1):3-15.

Ahmad A, Senapati S, Khan MI, Kumar R, Ramani R, Srinivas V, Sastry M. Intracellular synthesis of gold nanoparticles by a novel alkalotolerantactinomycete, Rhodococcus species. Nanotechnology. 2003; 14(7):824.

Ahmad A, Senapati S, Khan MI, Kumar R, Sastry M. Extra/intracellular biosynthesis of gold nanoparticles by an alkalotolerant fungus, Trichothecium sp. Journal of Biomedical Nanotechnology. 2005; $1(1): 47-53$

Baldwin EA, Nisperos MO, Chen X, Hagenmaier RD. Improving storage life of cut apple and potato with edible coating. Postharvest Biology and Technology. 1996; 9(2):151-63.

Banks NH, Dadzie BK, Cleland DJ. Reducing gas exchange of fruits with surface coatings. Postharvest biology and technology. 1993; 3(3):269-84.

Boccuni F, Rondinone B, Petyx C, Iavicoli S. Potential occupational exposure to manufactured nanoparticles in Italy. Journal of cleaner production. 2008; 16(8):949-56.

Borm P, Klaessig FC, Landry TD, Moudgil B, Pauluhn J, Thomas K, Trottier R, Wood S. Research strategies for safety evaluation of nanomaterials, part V: role of dissolution in biological fate and effects of nanoscale particles. Toxicological Sciences. 2006; 90(1):23-32.

Burg TP, Godin M, Knudsen SM, Shen W, Carlson G, Foster JS, Babcock K, Manalis SR. Weighing of biomolecules, single cells and single nanoparticles in fluid. Nature. 2007; 446(7139):1066-9.

Castro-Mayorga J L, Fabra M J,Lagaron J M.. Stabilized nanosilver based antimicrobial poly (3-hydroxybutyrate-co-3hydroxyvalerate) nanocomposites of interest in active food packaging. Innovative Food Science \& Emerging Technologies, 2016; 33, 524-533.

Chen X, Jia B, Zhang Y, Gu M. Exceeding the limit of plasmonic light trapping in textured screen-printed solar cells using $\mathrm{Al}$ nanoparticles and wrinkle-like graphene sheets. Light: Science \& Applications. 2013; 2(8): e92.

Chen Z, Meng H, Xing G, Chen C, Zhao Y, Jia G, Wang T, Yuan H, Ye C, Zhao F, Chai Z. Acute toxicological effects of copper nanoparticles in vivo. Toxicology letters. 2006; 163(2):109-20.

Couch L M, Wien M, Brown J L, Davidson P. Food nanotechnology: Proposed uses, safety concerns and regulations. Agro FOOD Industry Hi Tech, 2016; 27, 1.

De Jong WH, Borm PJ. Drug delivery and nanoparticles: applications and hazards. International journal of nanomedicine. 2008 ;3(2):133.

Dhandapani P, Siddarth AS, Kamalasekaran S, Maruthamuthu S, Rajagopal G. Bio-approach: ureolytic bacteria mediated synthesis of ZnOnanocrystals on cotton fabric and evaluation of their antibacterial properties. Carbohydrate polymers. 2014; 103:448-55.

Duncan TV. Applications of nanotechnology in food packaging and food safety: barrier materials, antimicrobials and sensors. Journal of colloid and interface science. 2011;363(1):1-24.

Eltayeb M, Stride E, Edirisinghe M. Preparation, characterization and release kinetics of ethylcellulose nanoparticles encapsulating ethylvanillin as a model functional component. Journal of Functional Foods. 2015; 14:726-35.

Farhoodi M. Nanocomposite Materials for Food Packaging Applications: Characterization and Safety Evaluation. Food Engineering Reviews, 2016; 8(1), 35-51.

Ferreira RV, Pereira IL, Cavalcante LC, Gamarra LF, Carneiro SM, AmaroJr E, Fabris JD, Domingues RZ, Andrade AL. Synthesis and characterization of silica-coated nanoparticles of magnetite. Hyperfine Interactions. 2010; 195(1-3):265-74.

Fortunati E, Peltzer M, Armentano I, Jiménez A, Kenny JM. Combined effects of cellulose nanocrystals and silver nanoparticles on the barrier and migration properties of PLA nano-biocomposites. Journal of Food Engineering. 2013; 118(1):117-24.

Fu Y, Li P, Wang T, Bu L, Xie Q, Xu X, Lei L, Zou C, Chen J, Yao S. Novel polymeric bionanocomposites with catalytic Pt nanoparticles label immobilized for high performance amperometric immunoassay. Biosensors and Bioelectronics. 2010; 25(7):1699-704.

Gade AK, Bonde P, Ingle AP, Marcato PD, Duran N, Rai MK. Exploitation of Aspergillus niger for synthesis of silver nanoparticles. Journal of Biobased Materials and Bioenergy. 2008; 2(3):243-7.

Govender Y, Riddin T, Gericke M, Whiteley CG. Bioreduction of platinum salts into nanoparticles: a mechanistic perspective. Biotechnology letters. 2009; 31(1):95-100.

Govindaraju K, Kiruthiga V, Kumar VG, Singaravelu G. Extracellular synthesis of silver nanoparticles by a marine alga, SargassumwightiiGrevilli and their antibacterial effects. Journal of Nanoscience and Nanotechnology. 2009; 9(9):5497-501.

Habib AH, Ondeck CL, Chaudhary P, Bockstaller MR, McHenry ME. Evaluation of iron-cobalt/ferrite core-shell nanoparticles for cancer thermotherapy. Journal of Applied Physics. 2008; 103(7):07A307.

Hejri A, Khosravi A, Gharanjig K, Hejazi M. Optimisation of the formulation of $\beta$-carotene loaded nanostructured lipid carriers prepared by solvent diffusion method. Food chemistry. 2013; 141(1):117-23.

Helland A, Kastenholz H, Thidell A, Arnfalk P, Deppert K. Nanoparticulate materials and regulatory policy in Europe: An analysis of stakeholder perspectives. Journal of Nanoparticle Research. 2006; 8(5):709-19. 
Horn D, Rieger J. Organic nanoparticles in the aqueous phasetheory, experiment, and use. AngewandteChemie International Edition. 2001; 40(23):4330-61.

Huang J, Li Q, Sun D, Lu Y, Su Y, Yang X, Wang H, Wang Y, Shao W, He N, Hong J. Biosynthesis of silver and gold nanoparticles by novel sundried Cinnamomumcamphoraleaf. Nanotechnology. 2007; 18(10):105104.

Jakubinek MB, White MA, Li G, Jayasinghe C, Cho W, Schulz MJ, Shanov V. Thermal and electrical conductivity of tall, vertically aligned carbon nanotube arrays. Carbon. $2010 ; 48(13): 3947-52$.

Jamshidian M, Tehrany EA, Imran M, Jacquot M, Desobry S. Poly-Lactic Acid: production, applications, nanocomposites, and release studies. Comprehensive Reviews in Food Science and Food Safety. 2010; 9(5):552-71.

Kahn ML, Cardinal T, Bousquet B, Monge M, Jubera V, Chaudret B. Optical properties of zinc oxide nanoparticles and nanorods synthesized using an organometallic method. ChemPhysChem. 2006; 7(11):2392-7.

Kanmani P, Rhim JW. Physicochemical properties of gelatin/silver nanoparticle antimicrobial composite films. Food chemistry. 2014; 148:162-9.

Kesisoglou F, Panmai S, Wu Y. Nanosizing-oral formulation development and biopharmaceutical evaluation. Advanced drug delivery reviews. 2007; 59(7):631-44.

Khalaj M J, Ahmadi H, Lesankhosh R,Khalaj G. Study of physical and mechanical properties of polypropylene nanocomposites for food packaging application: Nano-clay modified with iron nanoparticles.Trends in Food Science \& Technology, 2016; 51, 41-48.

Kumar R, Howdle S, Münstedt H. Polyamide/silver antimicrobials: effect of filler types on the silver ion release. Journal of Biomedical Materials Research Part B: Applied Biomaterials. 2005; 75(2):311-9.

Kuzma J, Romanchek J, Kokotovich A. Upstream oversight assessment for agrifood nanotechnology: a case studies approach. Risk Analysis. 2008; 28(4):1081-98.

Lagaron JM, Cabedo L, Cava D, Feijoo JL, Gavara R, Gimenez E. Improving packaged food quality and safety. Part 2: Nanocomposites. Food Additives and Contaminants. 2005 ;22(10):994-8.

Li JF, Huang YF, Ding Y, Yang ZL, Li SB, Zhou XS, Fan FR, Zhang W, Zhou ZY, Ren B, Wang ZL. Shell-isolated nanoparticleenhanced Raman spectroscopy. Nature. 2010; 464(7287):392-5.

Llorens A, Lloret E, Picouet PA, Trbojevich R, Fernandez A. Metallic-based micro and nanocomposites in food contact materials and active food packaging. Trends in Food Science \& Technology. 2012; 24(1):19-29.

Lok CN, Ho CM, Chen R, He QY, Yu WY, Sun H, Tam PK, Chiu JF, Che CM. Proteomic analysis of the mode of antibacterial action of silver nanoparticles. Journal of Proteome research. 2006; 5(4):916-24.

Luo PG, Stutzenberger FJ. Nanotechnology in the detection and control of microorganisms. Advances in applied microbiology. 2008; 63:145-81.

Maity I, Rasale DB, Das AK. Sonication induced peptideappended bolaamphiphile hydrogels for in situ generation and catalytic activity of Pt nanoparticles. Soft Matter. 2012; 8(19):5301-8.

Manivasagan P, Venkatesan J, Kang KH, Sivakumar K, Park SJ, Kim SK. Production of $\alpha$-amylase for the biosynthesis of gold nanoparticles using Streptomyces sp. MBRC-82. International journal of biological macromolecules. 2015; 72:71-8.

Matthey D, Wang JG, Wendt S, Matthiesen J, Schaub R, Lægsgaard E, Hammer B, Besenbacher F. Enhanced bonding of gold nanoparticles on oxidized TiO2 (110). Science. 2007; 315(5819):1692-6.

McClements DJ, Decker EA, Park Y, Weiss J. Structural design principles for delivery of bioactive components in nutraceuticals and functional foods. Critical reviews in food science and nutrition. 2009; 49(6):577-606

Mohite VS, Mahadik MA, Kumbhar SS, Kothavale VP, Moholkar AV, Rajpure KY, Bhosale CH. Photoelectrocatalytic degradation of benzoic acid using sprayed TiO 2 thin films. Ceramics International. 2015; 41(2):2202-8.
Mortazavi V, Nahrkhalaji MM, Fathi MH, Mousavi SB, Esfahani BN. Antibacterial effects of sol-gel-derived bioactive glass nanoparticle on aerobic bacteria. Journal of Biomedical Materials Research Part A. 2010; 94(1):160-8.

Mukherjee 4, Roy M, Mandal BP, Dey GK, Mukherjee PK, Ghatak J, Tyagi AK, Kale SP. Green synthesis of highly stabilized nanocrystalline silver particles by a non-pathogenic and agriculturally important fungus T. asperellum. Nanotechnology. 2008; 19(7):075103.

Mukherjee DK, Mondal A, Das A. Alcohol Oxidation in Ionic Liquids Catalysed by Recyclable Platinum Nanoparticles: A Green Approach. Journal of Catalyst \& Catalysis. 2014; 1(1):20-32.

Park JW, Testin RF, Vergano PJ, Park HJ, Weller CL. Fatty acid distribution and its effect on oxygen permeability in laminated edible films. Journal of food science. 1996; 61(2):401-6.

Prashanth KH, Tharanathan RN. Chitin/chitosan: modifications and their unlimited application potential - an overview. Trends in food science \& technology. 2007; 18(3):117-31.

Pusztai A, Bardocz S. The future of nanotechnology in food science and nutrition: Can science predict its safety. Nanotechnology: Risk, ethics and law. 2006: 167-79.

Quintanilla-Carvajal MX, Camacho-Díaz BH, Meraz-Torres LS, Chanona-Pérez JJ, Alamilla-Beltrán L, Jimenéz-Aparicio A, Gutiérrez-López GF. Nanoencapsulation: a new trend in food engineering processing. Food Engineering Reviews. 2010; 2(1):39-50.

Quintanilla-Carvajal MX, Hernandez-Sanchez H, AlamillaBeltran L, Zepeda-Vallejo G, Jaramillo-Flores ME, de JesúsPerea-Flores M, Jimenez-Aparicio A, Gutiérrez-López GF. Effects of microfluidisation process on the amounts and distribution of encapsulated and nonencapsulated $\alpha$-tocopherol microcapsules obtained by spray drying. Food Research International. 2014; 63:2-8.

Rai M, Yadav A, Gade A. Silver nanoparticles as a new generation of antimicrobials. Biotechnology advances. 2009; 27(1):76-83.

Reddy KM, Feris K, Bell J, Wingett DG, Hanley C, Punnoose A. Selective toxicity of zinc oxide nanoparticles to prokaryotic and eukaryotic systems. Applied physics letters. 2007; 90(21):213902.

Rhim JW. Effect of clay contents on mechanical and water vapor barrier properties of agar-based nanocomposite films. Carbohydrate polymers. 2011; 86(2):691-9.

Sadeghnejad A, Aroujalian A, Raisi A, Fazel S. Antibacterial nano silver coating on the surface of polyethylene films using corona discharge. Surface and Coatings Technology. 2014; 245:1-8.

Saeidnia S, Abdollahi M. Toxicological and pharmacological concerns on oxidative stress and related diseases. Toxicology and applied pharmacology. 2013; 273(3):442-55

Saharan B S, SharmaD, Sahu R, Sahin O, Warren A. Towards algal biofuel production: a concept of green bio energy development Innovative Romanian Food Biotechnology, 2013; 12, 1.

Sanguansri P, Augustin MA. Nanoscale materials developmenta food industry perspective. Trends in Food Science \& Technology. 2006; 17(10):547-56.

Sanguansri P, Augustin MA. Nanoscale materials developmenta food industry perspective. Trends in Food Science \& Technology. 2006; 17(10):547-56.

Sanpui P, Murugadoss A, Prasad PD, Ghosh SS, Chattopadhyay A. The antibacterial properties of a novel chitosan-Ag-nanoparticle composite. International journal of food microbiology. 2008; 124(2):1426.

Sekhon, B. S. Food nanotechnology-an overview. Nanotechnology, science and applications.(2010) 3,1.

Shahverdi AR, Fakhimi A, Shahverdi HR, Minaian S. Synthesis and effect of silver nanoparticles on the antibacterial activity of different antibiotics against Staphylococcus aureus and Escherichia coli. Nanomedicine: Nanotechnology, Biology and Medicine. 2007; 3 (2):168-71.

Sharma D, Saharan BS, Chauhan N, Bansal A, Procha S. Production and structural characterization of Lactobacillus helveticus derived biosurfactant. The Scientific World Journal, 2014. 
Sharma D, Saharan BS. Functional Characterization of Biomedical Potential of Biosurfactant Produced by Lactobacillus helveticus. 2016; Biotechnology Reports.

Sinha R, Kim GJ, Nie S, Shin DM. Nanotechnology in cancer therapeutics: bioconjugated nanoparticles for drug delivery. Molecular cancer therapeutics. 2006; 5(8):1909-17.

Sorrentino A, Gorrasi G, Vittoria V. Potential perspectives of bio-nanocomposites for food packaging applications. Trends in Food Science \& Technology. 2007; 18(2):84-95.

Souza VGL, Fernando A L. Nanoparticles in food packaging: Biodegradability and potential migration to food-A review. Food Packaging and Shelf Life, 2016; 8, 63-70.

Sudha SS, Rajamanickam K, Rengaramanujam J. Microalgae mediated synthesis of silver nanoparticles and their antibacterial activity against pathogenic bacteria (2013).

Teisala H, Tuominen M, Aromaa M, Stepien M, Mäkelä JM, Saarinen JJ, Toivakka M, Kuusipalo J. Nanostructures increase water droplet adhesion on hierarchically rough superhydrophobic surfaces. Langmuir. 2012; 28(6):3138-45.

Teixeira ED, Pasquini D, Curvelo AA, Corradini E, Belgacem MN, Dufresne A. Cassava bagasse cellulose nanofibrils reinforced thermoplastic cassava starch. Carbohydrate polymers. 2009; 78(3):422-31.

Thakkar KN, Mhatre SS, Parikh RY. Biological synthesis of metallic nanoparticles. Nanomedicine: Nanotechnology, Biology and Medicine. 2010; 6(2):257-62.

Tiede K, Boxall AB, Tear SP, Lewis J, David H, Hassellöv M. Detection and characterization of engineered nanoparticles in food and the environment. Food Additives and Contaminants. 2008; 25(7):795-821.

Tsai SJ, Huang RF, Ellenbecker MJ. Airborne nanoparticle exposures while using constant-flow, constant-velocity, and air-curtainisolated fume hoods. Annals of occupational hygiene. 2010;54(1):78-87.

Tyagi P, Chandra S, Saraswat BS, Sharma D. Design, spectral characterization, DFT and biological studies of transition metal complexes of Schiff base derived from 2-aminobenzamide, pyrrole and furan aldehyde. SpectrochimicaActa Part A: Molecular and Biomolecular Spectroscopy, 2015; 143, 1-11.
Vähä-Nissi M, Hirvikorpi T, Mustonen T, Karppinen M, Harlin A. Thin film deposition techniques-steps towards more sustainable packages. 2010. TAPPI International Conference on Nanotechnology for the Forest Product Industry.

Weiss J, Takhistov P, McClements DJ. Functional materials in food nanotechnology. Journal of food science. 2006; 71(9):R107-16.

Xie J, Jon S. Magnetic nanoparticle-based theranostics. Theranostics. 2012; 2(1):122-4.

Xiong Z, Zhao D, Pan G. Rapid and complete destruction of perchlorate in water and ion-exchange brine using stabilized zero-valent iron nanoparticles. Water research. 2007; 41(15):3497-505.

Yang K, Jung H, Lee HR, Lee JS, Kim SR, Song KY, Cheong E, Bang J, Im SG, Cho SW. Multiscale, hierarchically patterned topography for directing human neural stem cells into functional neurons. ACS nano. 2014; 8(8):7809-22.

Youssef AM, Kamel S, El-Samahy MA. Morphological and antibacterial properties of modified paper by PS nanocomposites for packaging applications. Carbohydrate polymers. 2013; 98(1):1166-72.

Zheng L, Brody JP, Burke PJ. Electronic manipulation of DNA, proteins, and nanoparticles for potential circuit assembly. Biosensors and Bioelectronics. 2004; 20(3):606-19.

\section{How to cite this article:}

Sharma D, Dhanjal DS. Bio-Nanotechnology for Active Food Packaging. J App Pharm Sci, 2016; 6 (09): 220-226. 